$$
\begin{aligned}
& \text { RECEIVED } \\
& \text { OCT O } 71996 \\
& \text { OSTI }
\end{aligned}
$$

\title{
DEVELOPING, TESTING, EVALUATING AND OPTIMIZING SOLAR HEATING SYSTEMS
}

\section{PROJECT STATUS REPORT FOR} JUNE AND JULY 1996

\author{
Prepared for: \\ U.S. Department of Energy \\ Conservation and Renewable Energy \\ Under Grant DE-FG36-95G010093 \\ Submitted by: \\ Solar Energy Applications Laboratory \\ Colorado State University

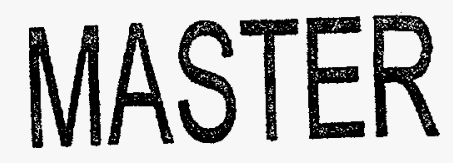 \\ October 1996




\section{DISCLAIMER}

Portions of this document may be illegible in electronic image products. Images are produced from the best available original document. 


\section{DISCLAIMER}

This report was prepared as an account of work sponsored by an agency of the United States Government. Neither the United States Government nor any agency thereof, nor any of their employees, makes any warranty, express or implied, or assumes any legal liability or responsibility for the accuracy, completeness, or usefulness of any information, apparatus, product, or process disclosed, or represents that its use would not infringe privately owned rights. Reference herein to any specific commercial product, process, or service by trade name, trademark, manufacturer, or otherwise does not necessarily constitute or imply its endorsement, recommendation, or favoring by the United States Government or any agency thereof. The views and opinions of authors expressed herein do not necessarily state or reflect those of the United States Government or any agency thereof. 


\section{UNIQUE SOLAR SYSTEM COMPONENTS}

\section{INTEGRATED TANK/HEAT EXCHANGER MODELING/EXPERIMENTS}

Work continues on the development of an improved wrap-around heat exchanger/tank model. The focus of the effort during June and July has been on evaluating various "local" methods of evaluating the natural convection boundary layer for use in a two layer model of the natural convection in the tank. The advantage of a local method is that the solution of the boundary layer equations depends on one or more parameters, but not on the upstream solutions. As a result, the solutions of the boundary layer equations can be calculated in advance and tabulated for use in the tank model.

Similarity solutions are examples of local solutions. After transformation, the boundary layer are independent of the streamwise coordinate. The equations need be solved only once. The heat transfer and/or temperature difference at any streamwise location is then calculated by scaling the solutions with local boundary conditions. A similarity solutions is considered exact to the extent that it represents an exact solution of the boundary layer equations. That is no terms in the boundary layer equations are neglected. The problem is that similarity solutions are possible for only a very limited variation of the boundary conditions. Only power-law and exponential variation of surface temperature or heat flux with, at most, a proportional variation in the freestream temperature lead to similarity solutions for the natural convection boundary layer.

Local similarity refers to the application of a particular similarity solution to a problem in which the conditions for similarity are now exactly met. Essentially, any sources of nonsimilarities in the problem are neglected and the similarity solution is applied using the local boundary conditions. The use of an empirical natural convection heat transfer correlation in the original incarnation of the CSU wrap-around heat exchanger model is essentially an application of local similarity. The main difficulty with this approach is that there is no way to gage the error incurred.

The next level of approximation is referred to as locally nonsimilar solution methods. All of these methods make some attempt to account for nonsimilar terms in the boundary layer equations in some approximate way with varying degrees of success. Methods that fall into this category are Sparrow's local nonsimilarity method $(1971,1974)$, Kao's asymptotic expansion method $(1974,1976,1977)$, and Webb's modified local similarity method $(1989,1990,1995)$. Each of these methods are being considered for use in the new wrap-around heat exchanger model.

Regardless of the method chosen, the similar or pseudo-similar boundary layer equations must be solved numerically. Computer programs for two commonly used numerical solution techniques have been developed. The first is a shooting method outlined by Nachtsheim and Swigert (1965). The second is an implicit finite difference method developed by Keller (1971, Cebeci 1988) to solve the boundary layer equations and other parabolic partial difference equations.

\section{References}

Cebeci, T., and P. Bradshaw, Physical and Computational Aspects of Convective Heat Transfer, Springer-Verlag, New York, New York, 1988. 
Kao, T., "An Asymptotic Method for the Computation of Laminar Shear Stress and Heat Flux in Forced and Free Convection," PhD Dissertation, Department of Mechanical Engineering, Columbia University, N. Y., 1974.

Kao, T-T., "Locally Nonsimilar Solution for Laminar Free Convection Adjacent to a Vertical Wall," Journal of Heat Transfer, Vol.. 98, No. 2, pp. 321-322, May, 1976.

Kao, T-T., G. A. Domoto, H. G. Elrod, Jr., "Free Convection Along a Nonisothermal Flat Plate," Journal of Heat Transfer, Vol. 99, No. 1, pp. 72-78, February, 1977.

Keller, H. B., "A New Difference Scheme for Parabolic Problems, "Numerical Solution of Partial Differential Equations - II," Proceedings of the Second Symposium on the Numerical Solution of Partial Differential Equations, SYNSPADE 1970, College Park, Maryland, May 11-15, 1970, pp. 327-350, B. Hubbard, ed., Academic Press, New York, 1971.

Nachtsheim, P. R., and P. Swigert, "Statisfaction of Asymptotic Boundary Conditions in the Numerical Solution of Systems of Nonlinear Equations of Boundary-Layer Type," NASATN-D-3004, 1965.

Nachtsheim, P. R., and P. Swigert, "Satisfaction of Asymptotic Boundary Conditions in the Numerical Solution of Boundary-Layer Equations," Developments in Mechanics:

Proceedings of the Ninth Midwestern Mechanics Conference, Vol. 9, No. 2, pp. 361-371, University of Wisconsin, Madison, 1965.

Minjowycz, C. J., and E. M. Sparrow, "Local Nonsimilar Solutions for Natural Convection on a Vertical Cylinder," Journal of Heat Transfer, pp. 178-183, May, 1974.

Sparrow, E. M., H. Quack, and C. J. Boerner, "Local Nonsimilarity Boundary Layer Solutions," AIAA Journal, Vol. 8, No. 11, pp. 1936-1942, November, 1971.

Sparrow, E. M., and H. S. Yu, "Local Non-Similarity Thermal Boundary-Layer Solutions," Journal of Heat Transfer, pp. 328-334, November, 1971.

Webb, S. W., Calculation of Natural Convection Boundary Layer Profiles Using the Local Similarity Approach Including Turbulence and Mixed Convection, , Sandia National Laboratories Report SAND88-0821, 1989.

Webb, S. W., "A Local Similarity Model for Turbulent Natural Convection Along a Vertical Surface" ASME HTD-Vol. 140, Fundamentals of Natural Convection, AIAA/ASME Thermophysics and Heat Transfer Conference, Seattle, WA., pp. 105-112, June 18-20, 1990.

Webb, S. W., "Modified Local Similarity For Natural Convection Along a Nonisothermal Vertical Flat Plate Including Stratification" ASME HTD-Vol. 107, Proceedings of the 30th National Heat Transfer Conference, Vol. 8, Portland, OR, pp. 123-130, August 6-8, 1995. 


\section{ADVANCED RESIDENTIAL SOLAR DOMESTIC HOT WATER (SDHW) SYSTEMS}

This report is for June and July, 1996.

\section{Experimental Work}

The current emphasis of this work is the use of energy draw data from short-term tests for validating system performance. Almost all of the effort during June and July was expended on obtaining and delivering data sets.

- Data sets were obtained under the conditions of zero auxiliary heat, three draws done daily at 0800,1200 and 1600 hours Mountain Daylight Time, and normal controller settings.

- Data sets were obtained for the days of July 7, July 8, July 16 and July 27, 1996.

- $\quad$ Data sets are described in the attached paper, "System Descriptions and Tests."

- Data sets are available via anonymous ftp from $\mathrm{k} 12$.colostate.edu in subdirectory pub/Burns/SEAL. Data files for each day exist in a separate subdirectory at this level, named the date of the test.

Subsequent conversation with Jay Burch resulted in the conclusion that the data sets were of limited value due to the fact that the systems were not purged with an energy-metering draw at the conclusion of the tests. Also, it was decided that no draws should be done during the tests, while three draws were done during the above tests.

\section{Optimization of Evacuated Tube Collectors}

This effort involves an array of evacuated tube collectors, which is being tested experimentally and simulated numerically. In the last progress report, the progress to date was given encompassing calibrations, and data collection using the specular backplane.

Specific tasks accomplished during these two months include:

- Additional outdoors tests were conducted on an array of eight NEG collectors, with different backplanes. Backplanes attributes were as follows: (1) black, (2) stainless steel (specular reflectance of about 0.6 ), and white paint (diffuse reflectance of about 0.7 ).

- Phase III of rewriting the IAM program, with the addition of refraction to the optical model of the glass covers, was completed. Joe Ryan, an MS student, performed additional testing and debugging. 


\section{SYSTEM DESCRIPTIONS AND TESTS \\ by}

\section{Patrick L. Bruckhart, Patrick J. Burns and Timothy A. Dierauf pbruck@lamar.colostate.edu,pburns@ACNS.colostate.edu, and tdierauf@lamar.colostate.edu \\ Solar Energy Applications Laboratory (SEAL) \\ Colorado State University \\ Fort Collins, CO 80523 \\ (970) $491-8494$}

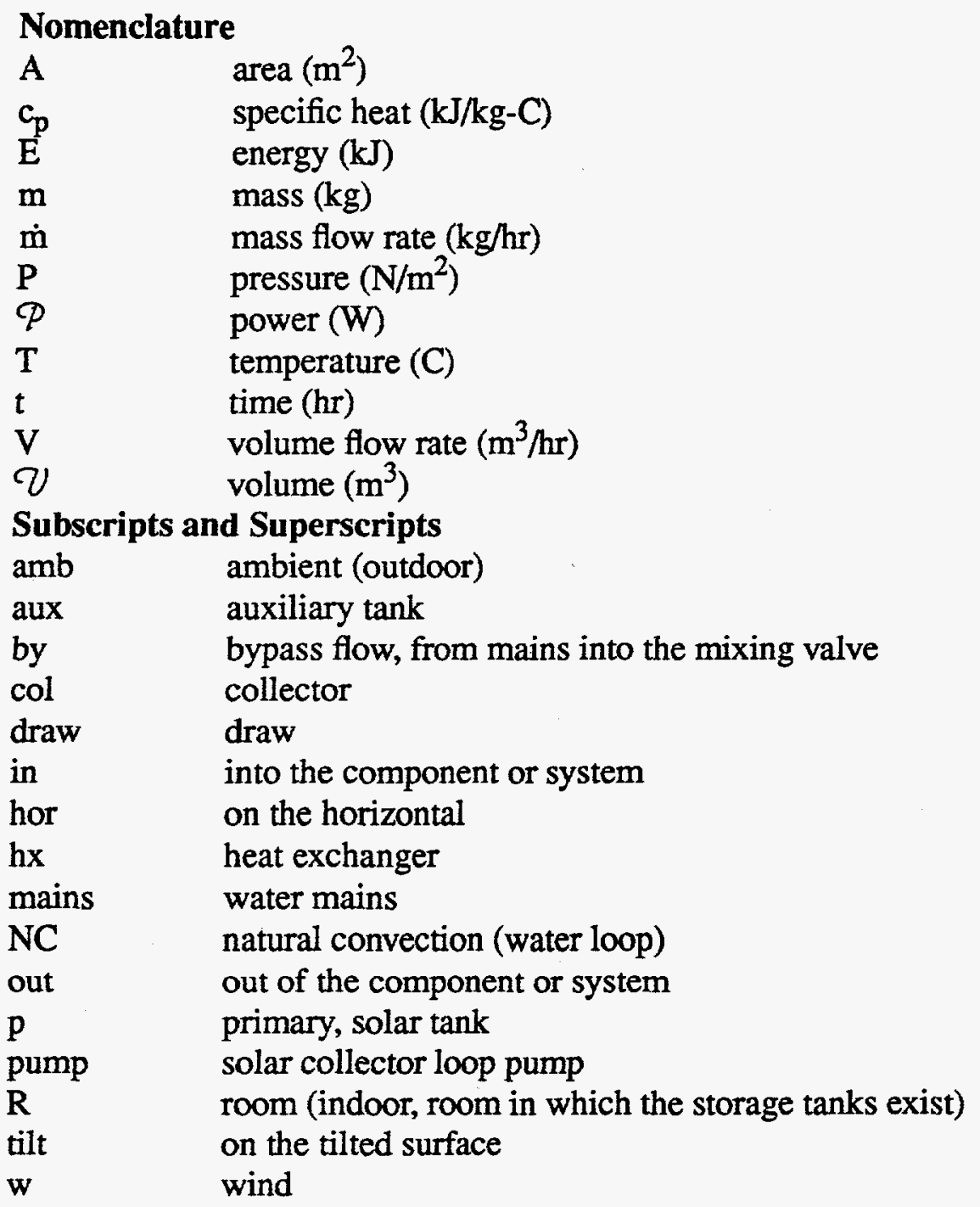

\section{Introduction}

This paper provides additional detail to accompany the data sets taken as part of our Solar Domestic Hot Water activity, sponsored by the Department of Energy. Descriptions of the physical systems tested are given in section 2 . The details of the measurements are given in section 
3.The testing procedures are presented in section 4 . The file formats and availability are given in section 5 .

\section{Physical Systems}

The two systems include: (1) an integral collector storage (ICS) system which uses a pump to circulate water between the solar storage (collectors) and the auxiliary storage tank, and (2) a natural convection heat exchanger (NCHX) system, utilizing glycol in the collector loop and water in the natural convection heat exchanger loop with the solar storage tank. Table 1 provides the system characteristics.

Table 1. System Characteristics

\begin{tabular}{|c|c|c|}
\hline System Characteristic & ICS & NCHX \\
\hline \hline Manufacturer & $\begin{array}{c}\text { Nippon Electric } \\
\text { Glass (NEG) }\end{array}$ & Thermodynamics \\
\hline Model & PK-20 & Solar Boiler \\
\hline Net Collector Area, $\mathrm{m}^{2}\left(\mathrm{ft}^{2}\right)$ & $3.00(32.3)^{\mathrm{a}}$ & $5.67(61.0)$ \\
\hline Primary Solar Tank Volume, $\mathrm{m}^{3}$ (gal.) & - & $0.21(56.4)$ \\
\hline Aux. Tank Volume, $\mathrm{m}^{3}\left(\mathrm{gal}^{\mathrm{s}}\right)$ & $0.14(36)$ & $0.14(36)$ \\
\hline Nominal Collector Flow Rate, $\mathrm{m}^{3} / \mathrm{s}$ & $5.9 \times 10^{-5}$ & $1.8 \times 10^{-5}$ \\
$\left(\mathrm{ft}^{3} / \mathrm{s}\right)$ & $\left(2.1 \times 10^{-3}\right)$ & $\left(6.4 \times 10^{-4}\right)$ \\
\hline Pump Motor Size, $\mathrm{W}(\mathrm{hp})$ & $7.5(1 / 100)$ & $248.6(1 / 3)$ \\
\hline Controller $\Delta \mathrm{T}$ - On/Off, ${ }^{\circ} \mathrm{C}$ & $12 / 4$ & $7 / 2$ \\
\hline
\end{tabular}

a. Aperture area, includes gaps between tubes

The collectors are mounted facing due south at a $45^{\circ}$ slope on the collector test bed located about $6.1 \mathrm{~m}(20 \mathrm{ft}$.) south of the basement of Solar House 1 at Colorado State University. Note that the aperture area is given for the ICS system. A TRNSYS IAM file is available from the authors for the ICS system. From there, piping is run into the basement of Solar House I, where all storage tanks (except the ICS collectors), pumps, and the external, natural convection heat exchanger are located. Also in the basement of Solar House I is the HP System 10 data acquisition system and the 80386 computer used for data logging. Labtech Notebook is used to control the acquisition, manipulation and storage of data. 
The plumbing to the solar collectors begins in the basement, travels through a small annex used to house a desiccant wheel (a run of $3.51 \mathrm{~m}$, or $11.5 \mathrm{ft}$ ), and then continues outdoors to the collectors (a run of $7.16 \mathrm{~m}$, or $23.5 \mathrm{ft}$ ). All systems are connected in parallel to both the water main supply line and the mixing valve to the hot water draw line (Figure 1). Except for the 0.0127 $m(1 / 2$ in.) sweated copper reducers/expanders near the pumps and the supply and return for the NCHX system (described later), all piping is $0.0187 \mathrm{~m}$ ( $3 / 4$ in.) sweated copper. All lines are well insulated thermally. To minimize pressure drop, all valves are $0.0187 \mathrm{~m}$ (3/4 in.) or $0.0127 \mathrm{~m}(1 / 2$ in.) (these $1 / 2$ inch valves are used to isolate only the pumps) through-flow ball valves.

\subsection{ICS System}

The ICS system consists of two collector modules, each with four evacuated tubes. Each evacuated tube contains $0.019 \mathrm{~m}^{3}$ ( 5 gallons) of integral storage. The inner tube which holds the water is coated with a selective surface of black chrome with an absorptance of 0.93 . The aperture area is $3.00 \mathrm{~m}^{2}\left(32.3 \mathrm{ft}^{2}\right)$. The two modules are connected in parallel. The heat loss coefficient of these collectors is sufficiently low such that they are able to maintain temperatures above freezing for several days of inclement weather and no freeze protection is required for the modules. However, the pipes to and from the collector are subject to freezing, and consequently, rupture, and are therefore are drained during periods of freezing weather.

The ICS system plumbing is shown in Figure 2. An induction pump, rated at $7.46 \mathrm{~W}$ (1) $100 \mathrm{hp}$ ) circulates the water between the collector storage and auxiliary tank at a nominal rate of $5.9 \times 10^{-5} \mathrm{~m}^{3} / \mathrm{s}(0.94 \mathrm{gpm})$. The pump was initially installed by the manufacturer to prevent overheating of the collectors. During a draw, the pump is inactivated due to the water mains supply pressure, when water mains supply flows out to the collectors. Since a draw is about $0.079 \mathrm{~m}^{3}(21$ gallons) in volume, essentially half of the water from each collector module is displaced with main supply water. The displaced collector water flows into the bottom of a standard auxiliary tank. During a draw, energy is removed from the top of the auxiliary tank.

The pump is operated by a differential controller with the upper dead band set at $12{ }^{\circ} \mathrm{C}$ and the lower dead band set at $4^{\circ} \mathrm{C}$. The thermistors that measure the temperature difference are located on the outlet of the collector and on the bottom of the auxiliary storage tank.

\subsection{Natural Convection Heat Exchanger (NCHX) System}

The NCHX system consists of two standard $1.2 \mathrm{~m} \times 2.4 \mathrm{~m}$ ( $4 \mathrm{ft}$. $\mathrm{x} 8 \mathrm{ft}$.) micro-flow collectors connected in series. The solar absorber consists of two aluminum fins metallurgically bonded to a copper tube and constructed in a serpentine fashion. The absorber plate is an anodic cobalt selective surface with an absorptance of 0.92 . The cover is manufactured of low-iron, tempered glass. The supply tubing to the collector is $0.0095 \mathrm{~m}$ ( $3 / 8 \mathrm{in}$.) diameter and the return tubing is $0.0064 \mathrm{~m}(1 / 4 \mathrm{in}$.) diameter. Each tube is $7.62 \mathrm{~m}(25 \mathrm{ft}$.) in length.

A system schematic is presented in Figure 3. This system utilizes $40 \%$ propylene glycol/ $60 \%$ water solution pumped from the heat exchanger to the collectors at a nominal rate of $1.8 \mathrm{x}$ $10^{-5} \mathrm{~m}^{3} / \mathrm{s}(0.3 \mathrm{gpm})$. The pump, an impeller type rated at $248.7 \mathrm{~W}(1 / 3 \mathrm{hp})$, is operated by a differential controller. The upper dead band is set at $7{ }^{\circ} \mathrm{C}$ and the lower dead band is set at $2{ }^{\circ} \mathrm{C}$. The thermistors that measure the controlling temperature difference are located on the outlet of the collectors and inside the heat exchanger shell.

Upon returning from the collectors, the glycol enters the coil of a high performance heat exchanger, located adjacent to the solar storage tank. The overall heat transfer coefficient for the heat exchanger is $380 \mathrm{~W} / \mathrm{m}^{2} \mathrm{~K}\left(67 \mathrm{Btu} / \mathrm{hr} \mathrm{ft}^{2}{ }^{\circ} \mathrm{F}\right)$. The heat exchanger is a shell and coil type with 
four copper coils enclosed in a copper shell. Each coil is a copper tube $30.48 \mathrm{~m}(100 \mathrm{ft}$.) in length and $0.0064 \mathrm{~m}\left(1 / 4 \mathrm{in}\right.$.) in diameter, with a heat exchanger area of $0.61 \mathrm{~m}^{2}\left(6.5 \mathrm{ft}^{2}\right)$. This tubing constitutes four concentric coils with an overall height of $0.41 \mathrm{~m}$ (16 in). The glycol flows in parallel through the four coils. This, together with the small diameter tubing to and from the collector, accounts for the pump being of much larger size than for the ICS system.

Water, inside the shell, circulates from the heat exchanger to the solar storage tank via natural convection, driven by the temperature difference between the hot glycol and the colder solar storage tank water. During a draw, mains supply flows into the bottom of the solar storage tank while the hot water at the top of the solar storage tank is transferred to the bottom of a $0.14 \mathrm{~m}^{3}$ (36 gallon) auxiliary tank. Energy is removed from the top of the auxiliary tank.

\section{Instrumentation and Measurements}

Instantaneous measurements are taken and logged every 15 seconds. Two types of data files are provided: (1) data averaged over five minute intervals, and (2) data, not averaged over time, at 15 second intervals. The former data files are useful in assessing overall system performance, and for comparison with simulation (i.e. TRNSYS). The latter data files are useful when one is interested in the details of the draws, and are indeed needed to calculate the energy draws accurately. Measurements are classified into two categories: (1) environmental (ambient weather station and indoor room temperature) measurements, and (2) systems measurements. These are described separately by section below.

\subsection{Environmental Data}

The weather station consists of two pyranometers used to measure horizontal and tilt radiation, a wind speed anemometer, a wind direction indicator, and a shielded, outdoor ambient temperature sensor. The horizontal pyranometer is located on the roof of Solar House 1, with an unobstructed view of the sky. The remainder of the weather station, including the tilt pyranometer (tilted at $45^{\circ}$, the collector slope), is located adjacent to the solar collectors, at a nominal height of $2 \mathrm{~m}$. Thus, the total tilt radiation, outdoor ambient temperature, wind speed and direction are indicative of the microclimate which the solar collectors experience. Also included along with the weather data are the shielded, indoor temperature readings, $T_{R}$, located in the room adjacent to the storage tanks.

\subsection{Common Systems Measurements}

Figure 1 shows the common piping diagram for the supply and drain. Note that the supply (mains) water is provided to the NEG collectors directly, the primary, solar tank of the NCHX system, and to the common mixing valve. The common, constant-temperature mixing valve is used to control the temperature of the draw from all systems. The set point on the mixing valve is between 55 and $56^{\circ} \mathrm{C}$. Note that the draws are controlled by a timer, nominally for seven minutes duration for each system, with a small time lag before the draw is taken from the second system. This is designed to produce constant-energy draws, which will be achieved, provided the temperature of the water from the auxiliary tanks is sufficiently high to achieve the set-point temperature, and the flow rate is approximately constant during the draw. This should happen in all cases, except during a cold start-up. For this reason, the mixing valve is not used during the cold-start tests. Instead hot water is drawn directly from the auxiliary tanks during these tests.

Note that the only flow rate measured is the total flow rate. The flow rates to the systems and the bypass can be calculated from an energy balance on the mixing valve. 


\subsection{Individual Systems Data}

The electrical power consumed by the circulating pumps and the auxiliary heaters are measured for both systems. The pressure differences across the pumps are also measured for both systems. Volume flow rates are measured at the locations shown on Figures 2 and 3. However, there is one exception to this; the mass flow rate is measured by the Micromotion flow meter, in the natural convection loop. For consistency, the mass flow rates measured here are converted to volume flow rates using an equation of state for the density of water. An equation of state for density is necessary to compute mass flow rates. Temperatures are measured as indicated on the system diagrams, in the piping and tanks. Each tank is divided into eight nodes, of equal volume and height. Eight temperature measurements are taken at the centroid of each nodes.

\subsection{Conversions}

All readings are converted to the engineering units shown in Section 5, and small values are set to zero. Raw data files and calibrations are available from the authors upon request.

\section{Test Procedures}

\subsection{Normal Operation}

The systems are allowed to operate normally, according to the controllers supplied with the systems (the on/off differentials are provided in Table 1). The present systems are tested in accordance with OG-300 procedures. The systems are operated from about 5:45 AM to about 8:30 PM Mountain Daylight Time (MDT). Draws are performed at three "solar" times, at 8:00 AM solar time, Noon solar time, and $4 \mathrm{PM}$ solar time. The draw flow rate is about $2 \times 10^{-4} \mathrm{~m}^{3} / \mathrm{s}(3$ $\mathrm{gpm}$ ) for seven minutes (under control of a timer), or approximately $0.08 \mathrm{~m}^{3}$ (21 gallons) per system per draw. The water drawn from the system tanks is tempered with mains water through a constant-temperature mixing valve, with the intent to achieve a constant energy flow during each draw. Note that the mixing valve is not used for the cold-start tests,. That is, for the cold-start tests, hot water is drawn directly from the auxiliary tanks without mixing it with mains water.

\subsection{Initial Conditions}

Two sets of initial conditions were established for the data sets. One initial condition is a "cold" start, where the systems are manually flushed with mains water, until the temperature everywhere in the system is below $20^{\circ} \mathrm{C}$, and close to isothermal. In all cases, the initial state of the system is available in the data files. A second initial condition is a "hot" start, where the systems have been allowed to come into equilibrium with the environment after several days of normal operation. The intent here is to achieve good temperature separation in the data.Initially, the systems are run for ten minutes, before turning on the pumps or auxiliary heaters, to establish a "zero" for the initial flows and heater conditions.

\subsection{Weather Conditions}

Two data sets are collected for each initial condition, one during a clear, sunny day, and another during a mostly cloudy day. The intent here is to achieve good irradiation separation in the data.

\section{Data Files}

\subsection{Availability}


Data files are available via anonymous ftp from $\mathrm{k} 12$.colostate.edu, in ASCII text format. This is a Unix system, and is case sensitive. After logging in as anonymous and providing your email address as a password, change(cd) into subdirectory pub/Burns/SEAL. The SEAL subdirectory contains additional subdirectories of the dates for the systems tests included in the subdirectory. The subdirectory names are given as mon-xx-9y, where $x x$ is the two-digit day of month mon, and $y$ represents the last digit of the year. Each systems test subdirectory contain the following files: (1) file README, describing the tests (dates and operating protocols), (2) three each five-minute averaged data sets, and (3) three each, unaveraged, 15 second draw data sets which contain only the data during the three daily draws for both systems. The three files at each time step are: (1) the environmental data, (2) the data for the ICS system, and (3) the data for the NCHX system.

The filenames follow the following convention. The prefix is either: (1) environ, (2) ics, or (3) nchx, denoting data classification. The suffix of the files is either: (1) $5 \mathrm{~m}$, or (2) $15 \mathrm{~s}$, denoting, respectively, 5 minute-averaged data, or 15 second data. Thus, file ics. $15 \mathrm{~s}$ contains the data particular to the ICS system, at 15 second intervals (i.e. all of the data).

\subsection{Fields and Column Headings}

Each of the data files consists of multiple columns (fields) of data, in fixed format, with at least one blank space between each field. The files can be read using Fortran format statements, or as free-form files. Each of the files contains two or more lines of field (column) headings, which must be deleted if used as input to TRNSYS. The first line consists of the variable names of the data, and the second line consists of the units for each field. Before using the files for the first time, it is suggested to view the files with a text editor, or using the Unix utilities head and tail.

\subsection{Format of Ambient Weather Data File - Files ambient.15s and ambient $5 \mathrm{~m}$}

$\begin{array}{clll}\frac{\text { Field }}{1} & & \text { Units } & \text { Description, Variable name } \\ 2 & (\mathrm{hr}) & \text { Time in hours and fractions of hours, i.e. 3.50 is 3:30 AM } \\ 3 & (\mathrm{C}) & \text { Outside ambient temperature, Tamb } \\ 4 & \left(\mathrm{~kJ} / \mathrm{hr}-\mathrm{m}^{2}\right) & \text { Inside ambient room temperature, TR } \\ 5 & \left(\mathrm{~kJ} / \mathrm{hr}^{2}-\mathrm{m}^{2}\right) & \text { Total irradiation on the horizontal, Ihor } \\ 6 & (\mathrm{~m} / \mathrm{hr}) & \text { Wind speed, Vw } \\ 7 & \text { (degrees) } & \text { Wind direction, } \theta \mathrm{w}\end{array}$

\subsection{Format of ICS System Data File - Files ics.15s and ics.5m}

\begin{tabular}{|c|c|}
\hline Field & Units \\
\hline 1 & (hr) \\
\hline 2 & (C) \\
\hline 3 & (C) \\
\hline 4 & (C) \\
\hline 5 & (C) \\
\hline 6 & (C) \\
\hline 7 & (C) \\
\hline 8 & (C) \\
\hline 9 & (C) \\
\hline 10 & (C) \\
\hline 11 & (C) \\
\hline
\end{tabular}

Quantity

Time in hours and fractions of hours, i.e. 3.50 is 3:30 AM

Collector "indoor" inlet temperature, Tin,col, $R$

Collector "outdoor" inlet temperature, Tin,col

Collector outlet temperature, Tout,col

Auxiliary tank inlet temperature, Tin,aux

Pump inlet temperature, Tin,pump

Water mains temperature, Tmains

Auxiliary tank inlet temperature to the mixing valve, Tin,mix,aux

Mixed draw temperature, Tdraw

Node 1 (top) auxiliary tank temperature, Taux, 1

Node 2 auxiliary tank temperature, Taux, 2 


$\begin{array}{lll}12 & \text { (C) } & \text { Node } 3 \text { auxiliary tank temperature, Taux,3 } \\ 13 & \text { (C) } & \text { Node } 4 \text { auxiliary tank temperature, Taux,4 } \\ 14 & \text { (C) } & \text { Node } 5 \text { auxiliary tank temperature, Taux,5 } \\ 15 & \text { (C) } & \text { Node } 6 \text { auxiliary tank temperature, Taux,6 } \\ 16 & (\mathrm{C}) & \text { Node } 7 \text { auxiliary tank temperature, Taux,7 } \\ 17 & (\mathrm{C}) & \text { Node } 8 \text { (bottom) auxiliary tank temperature, Taux, } 8 \\ 18 & \left(\mathrm{~m}^{3} / \mathrm{hr}\right) & \text { Collector volume flow rate, Vcol } \\ 19 & \left(\mathrm{~m}^{3} / \mathrm{hr}\right) & \text { Water mains supply volume flow rate, Vmains } \\ 20 & \left(\mathrm{~m}^{3} / \mathrm{hr}\right) & \text { Draw volume flow rate, Vdraw } \\ 21 & (\mathrm{~W}) & \text { Electrical power input to the pump, Epump } \\ 22 & (\mathrm{~W}) & \text { Electrical power input to the auxiliary tank, Eaux } \\ 23 & \left(\mathrm{~N} / \mathrm{m}^{2}\right) & \text { Pressure difference across the pump, DPpump }\end{array}$

\subsection{Format of NCHX System Data File - Files nchx.15s and nchx.5m}

\begin{tabular}{|c|c|c|}
\hline Field & Units & Quantity \\
\hline 1 & $(\mathrm{hr})$ & Time in hours and fractions of hours, i.e. 3.50 is $3: 30 \mathrm{AM}$ \\
\hline 2 & (C) & Collector inlet temperature (glycol), Tin,col \\
\hline 3 & (C) & Collector outlet temperature (glycol), Tout,col \\
\hline 4 & (C) & Heat exchanger inlet temperature (glycol), Tin,hx,col \\
\hline 5 & (C) & Pump outlet temperature, Tout,pump \\
\hline 6 & (C) & Heat exchanger inlet temperature (water), Tin,hx,p \\
\hline 7 & (C) & Heat exchanger outlet temperature (water), Tout,hx,p \\
\hline 8 & (C) & Water mains temperature, Tmains \\
\hline 9 & (C) & Node 1 (top) primary tank temperature, $\mathrm{Tp}, 1$ \\
\hline 10 & (C) & Node 2 primary tank temperature, $\mathrm{Tp}, 2$ \\
\hline 11 & (C) & Node 3 primary tank temperature, $\mathrm{Tp}, 3$ \\
\hline 12 & (C) & Node 4 primary tank temperature, $T p, 4$ \\
\hline 13 & (C) & Node 5 primary tank temperature, $\mathrm{Tp}, 5$ \\
\hline 14 & (C) & Node 6 primary tank temperature, Tp, 6 \\
\hline 15 & (C) & Node 7 primary tank temperature, $\mathrm{Tp}, 7$ \\
\hline 16 & (C) & Node 8 (bottom) primary tank temperature, $\mathrm{Tp}, 8$ \\
\hline 17 & (C) & Primary tank outlet temperature, Tout,p \\
\hline 18 & (C) & Node 1 (top) auxiliary tank temperature, Taux, 1 \\
\hline 19 & (C) & Node 2 auxiliary tank temperature, Taux, 2 \\
\hline 20 & (C) & Node 3 auxiliary tank temperature, Taux, 3 \\
\hline 21 & (C) & Node 4 auxiliary tank temperature, Taux, 4 \\
\hline 22 & (C) & Node 5 auxiliary tank temperature, Taux, 5 \\
\hline 23 & (C) & Node 6 auxiliary tank temperature, Taux, 6 \\
\hline 24 & (C) & Node 7 auxiliary tank temperature, Taux, 7 \\
\hline 25 & (C) & Node 8 (bottom) auxiliary tank temperature, Taux, 8 \\
\hline 26 & (C) & Auxiliary tank inlet temperature to the mixing valve, Tin,mix,aux \\
\hline 27 & & Mixed draw temperature, Tdraw \\
\hline 28 & $\left(\mathrm{~m}^{3} / \mathrm{hr}\right)$ & Collector volume flow rate (glycol), Vcol \\
\hline 29 & $\left(\mathrm{~m}^{3} / \mathrm{hr}\right)$ & Water mains supply volume flow rate, Vmains \\
\hline 30 & $\left(\mathrm{~m}_{3}^{3} / \mathrm{hr}\right)$ & Water loop volume flow rate, Vloop \\
\hline 31 & $\left(\mathrm{~m}^{3} / \mathrm{hr}\right)$ & Draw volume flow rate, Vdraw \\
\hline
\end{tabular}


$32(\mathrm{~kJ} / \mathrm{hr})$

Electrical power input to the pump, Epump

$33 \quad(\mathrm{~kJ} / \mathrm{hr}) \quad$ Electrical power input to the auxiliary tank, Eaux

$34 \quad\left(\mathrm{~N} / \mathrm{m}^{2}\right) \quad$ Pressure difference across the pump, DPpump

Figure 1 Common Piping Diagram

Figure 2 ICS System Schematic

Figure 3 NCHX System Schematic

\section{List of Figures}

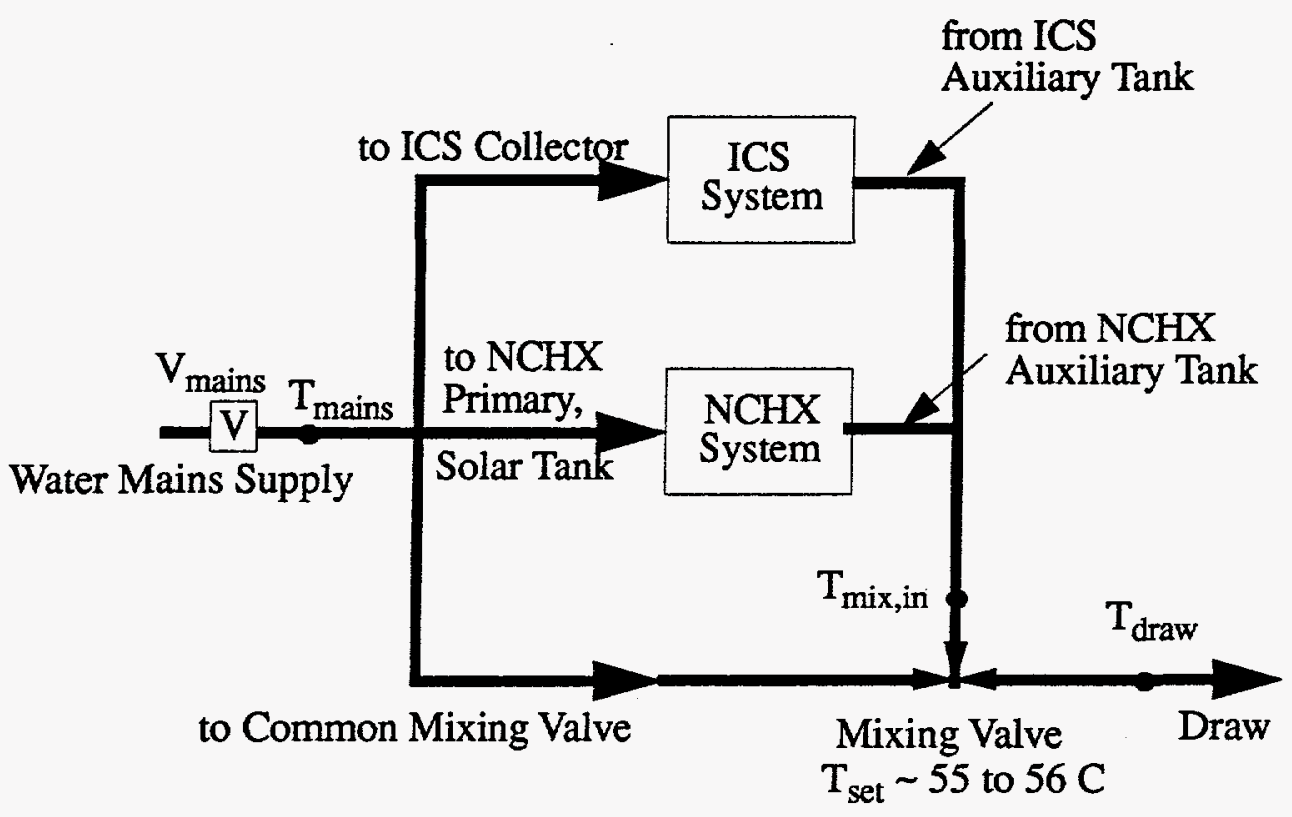

Figure 1 Common Piping Diagram 


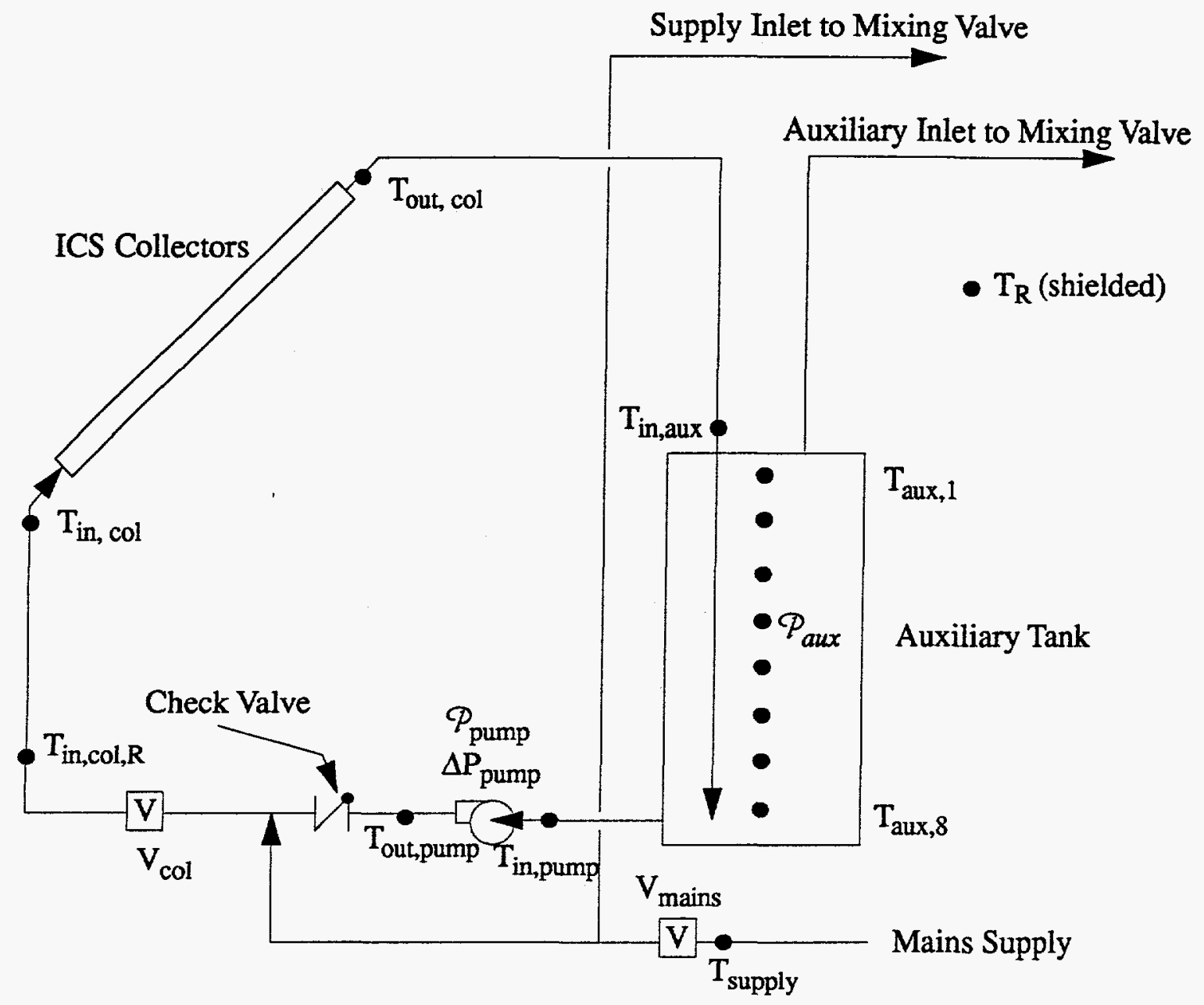

\begin{tabular}{|llll|}
\hline \multicolumn{3}{|c|}{ Legend } \\
$\mathrm{V}$ & Volume Flow Rate, $\mathrm{V}$ & $\mathcal{P}$ & Power \\
$\checkmark$ & Check Valve & $\Delta \mathrm{P}$ & Pressure Difference \\
$\square$ & Pump & $\bullet$ & Temperature, $\mathrm{T}$ \\
& Mixing Valve & & \\
\hline
\end{tabular}

Figure 2 ICS System Schematic 


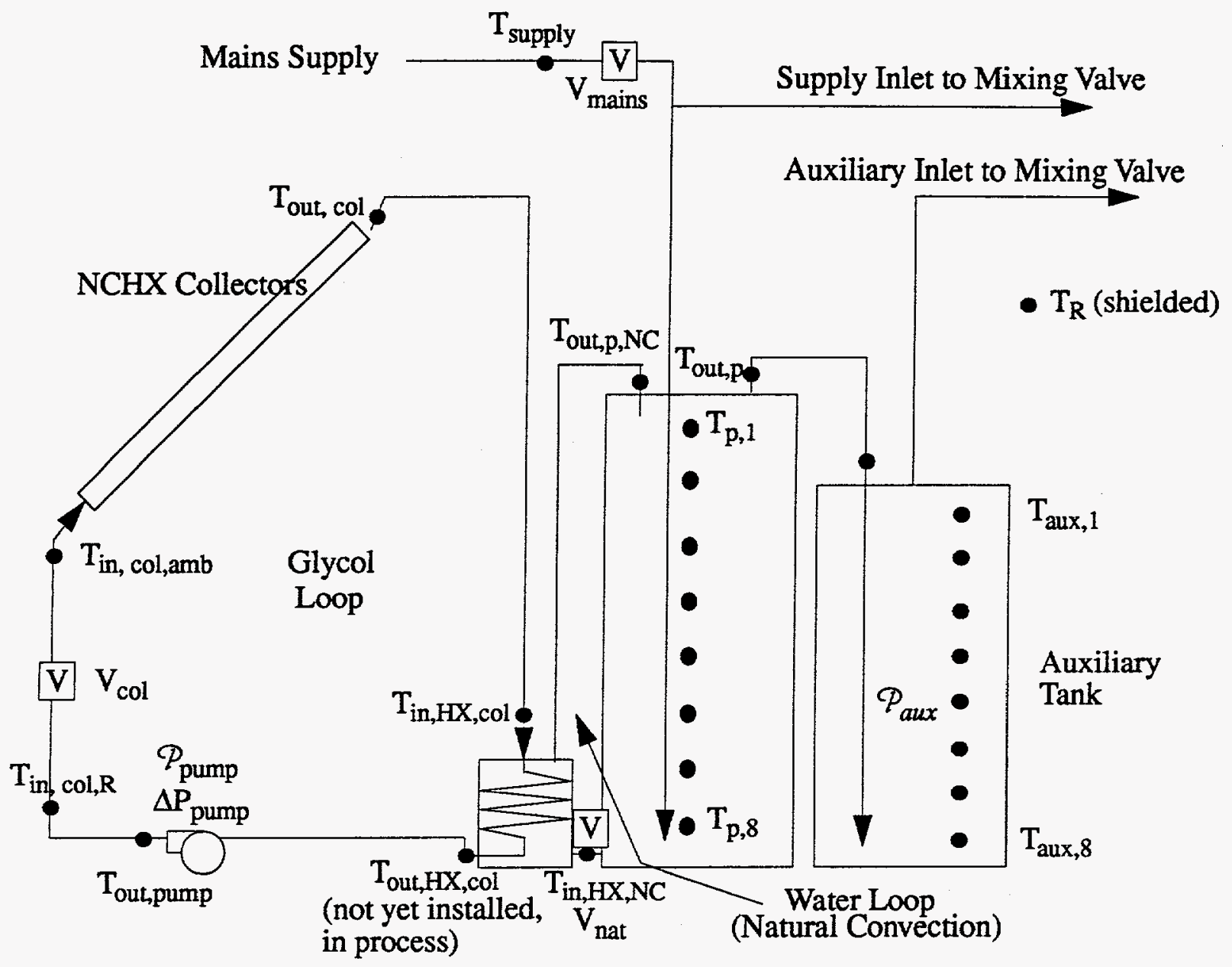

\begin{tabular}{|llll|}
\hline \multicolumn{3}{c}{ Legend } \\
V Volume Flow Rate, $V$ & $P$ & Power \\
$\square$ & Check Valve & $\Delta \mathrm{P}$ & Pressure Difference \\
& Pump & $\bullet$ & Temperature, $T$ \\
& Mixing Valve & & \\
\hline
\end{tabular}

Figure 3 NCHX System Schematic 


\section{Management and Coordination of Colorado State/DOE Program}

Coordination of research activities continued on the technical research tasks under the DOE grant, and accounts were maintained and updated. Financial and technical reports were submitted as required. 